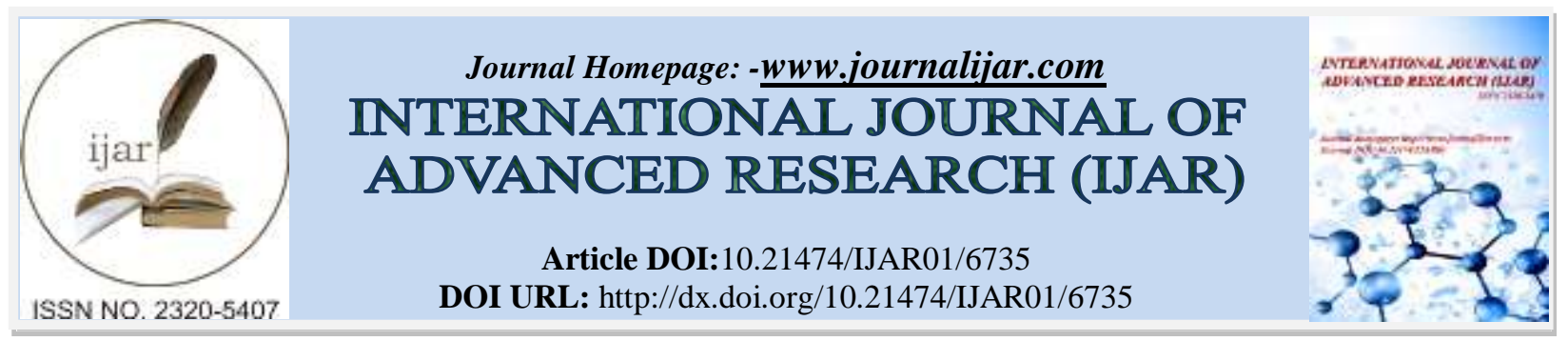

RESEARCH ARTICLE

\title{
PROSTHODONTIC REHABILITATION OF PATIENT WITH HYPOHYDROTIC ECTODERMAL DYSPLASIA.
}

\author{
Dr. Rashmi Sharma ${ }^{1}$, Capt Akhil Mittal ${ }^{2}$, Dr. Samridhi Thapa ${ }^{1}$, Dr. TK Giri ${ }^{3}$ and Dr. Sugata Mukherjee ${ }^{4}$ \\ 1. Pg student, Dept of Prosthodontics, Dr R Ahmed Dental College \& Hospital, Kolkata. \\ 2. MDS (Prosthodontics), Army Dental Corps. \\ 3. Professor, Dept Of Prosthodontics, Principal, Dr R Ahmed Dental College \& Hospital, Kolkata. \\ 4. HOD, Dept Of Prosthodontics, Dr R Ahmed Dental College \& Hospital, Kolkata.
}

\section{Manuscript Info}

Manuscript History

Received: 13 January 2018

Final Accepted: 15 February 2018

Published: March 2018

Keywords:-

Ectodermal dysplasia, Overdenture,

Rehabilitation, Oligodontia.

\section{Abstract}

Ectodermal dysplasia is a rare group of disorders affecting the hair, nails, teeth and sweat glands to a variable degree. Poor aesthetics due to missing teeth or abnormal tooth form may be the first indicator of the disorder. This case report describes the case of a patient who exhibited oligodontia with peg shaped teeth in a hypoplastic arches and was concerned about the poor appearance and difficulty in chewing.

Copy Right, IJAR, 2018,. All rights reserved.

\section{Introduction:-}

Ectodermal dysplasia is a rare, inherited, $\mathrm{X}$ linked recessive disorder. Classical triad of facial features of ED include sparse hair (atrichosis or hypotrichosis), abnormal or missing teeth (anodontia or hypodontia) and inability to sweat due to lack of sweat glands (anhidrosis or hypohidrosis) ${ }^{1}$. Other facial features include underdevelopment of alveolar ridges, frontal bossing, depressed nasal bridge, reduced vertical facial height etc. Therefore, the prosthetic rehabilitation of these patients is essential to restore aesthetics, mastication, phonetics and self esteem. This case report describes prosthetic rehabilitation of a patient with ectodermal dysplasia with a tooth supported overdenture and composite veneering.

\section{Case Report:-}

An 18 year old male patient presented with the chief complaint of difficulty in chewing and poor appearance. Extraoral examination revealed prominent forehead, thin and fragile hair, everted lips, had dry skin and decreased vertical dimension (Fig.1). Patient also reported that he was intolerant to high temperatures and thus presented the characteristic features of Hypohydrotic Ectodermal Dysplasia. Intra oral examination revealed presence of maxillary central incisors which were malformed and first molar teeth. Mandible had malformed canines and first molar teeth (Fig.2). Mouth was relatively dry because of decreased salivary flow. Alveolar ridges were not well devolped. Radiographic examination revealed oligodontia, hypotrophied alveolar arches, with absence of retained roots or tori (Fig.3). An Overdenture with composite veenering was planned as it would conserve the remaining natural teeth, preserve proprioception and provide retention, stability and support.

Primary impressions were made in irreversible hydrocolloid (algitex, DPI, Mumbai) and casts poured in type III dental stone (Kalabhai). Wax spacer was given and custom trays were fabricated in self polymerizing Methylmethacrylate resin (DPI, Mumbai). Secondary impressions 
were done using a putty light body dual stage technique (Affinis, Coltene Whaledent, NJ). The following procedure is of a conventional complete denture fabrication including facebow transfer, recording maxillomandibular relation and mounting on a semi adjustable articulator (Hanau Wide Vue) (fig. 4). Tooth selection was done according to tooth shade,size, facial form, following which the teeth arrangementwas done. Try in was done which was approved by the patient. After delivery of the finished and polished denture (Fig. 5), peg shaped central incisors were given the proper form using composite resin (tetric-n-ceram, Ivoclar whaldent). Overdentures restored the aesthetics and function of the patient (Fig. 6). Necessary adjustments were done after 48 hours of recall. Cleaning and hygiene maintenance instructions were given to the patient.
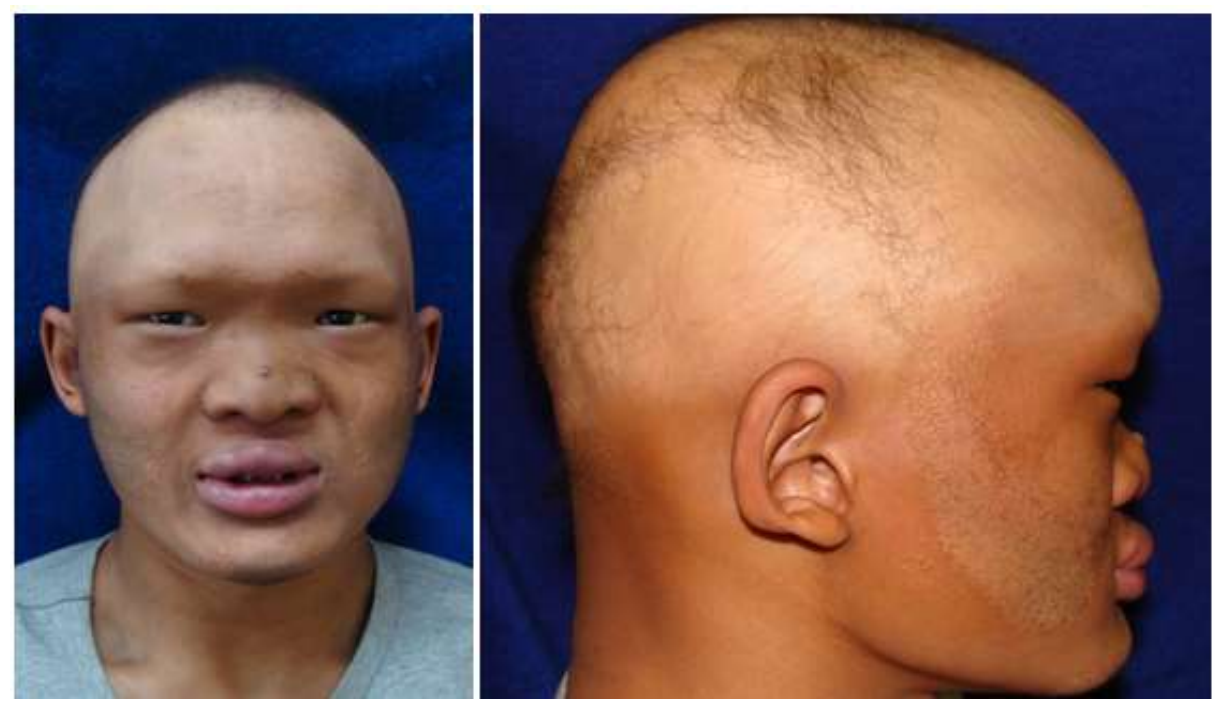

Fig. 1:- Facial features showing classical signs

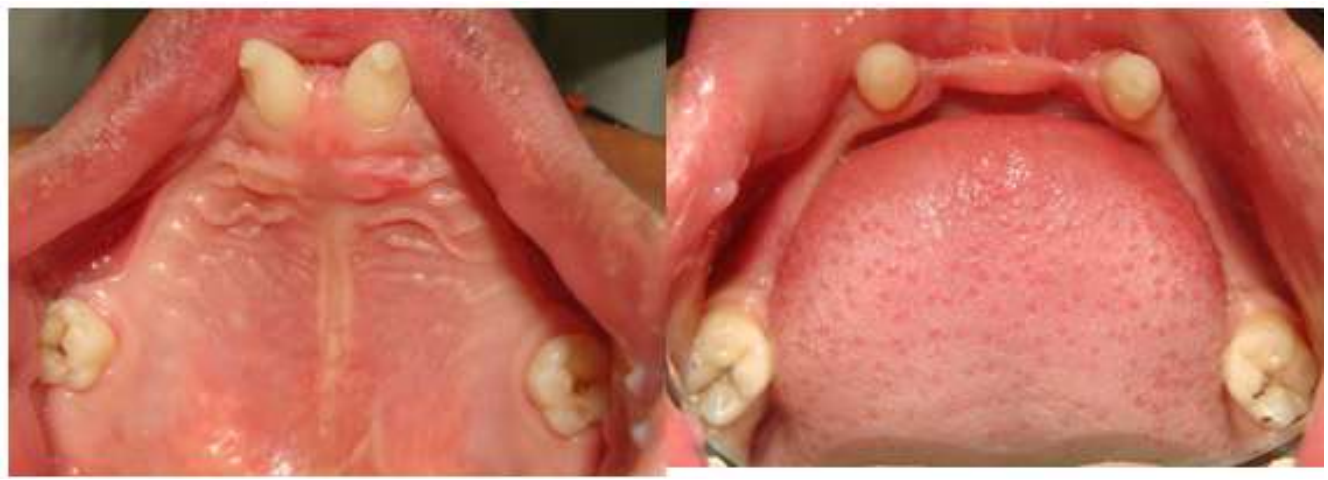

Fig. 2:- Intraoral view showing Oligodontia 


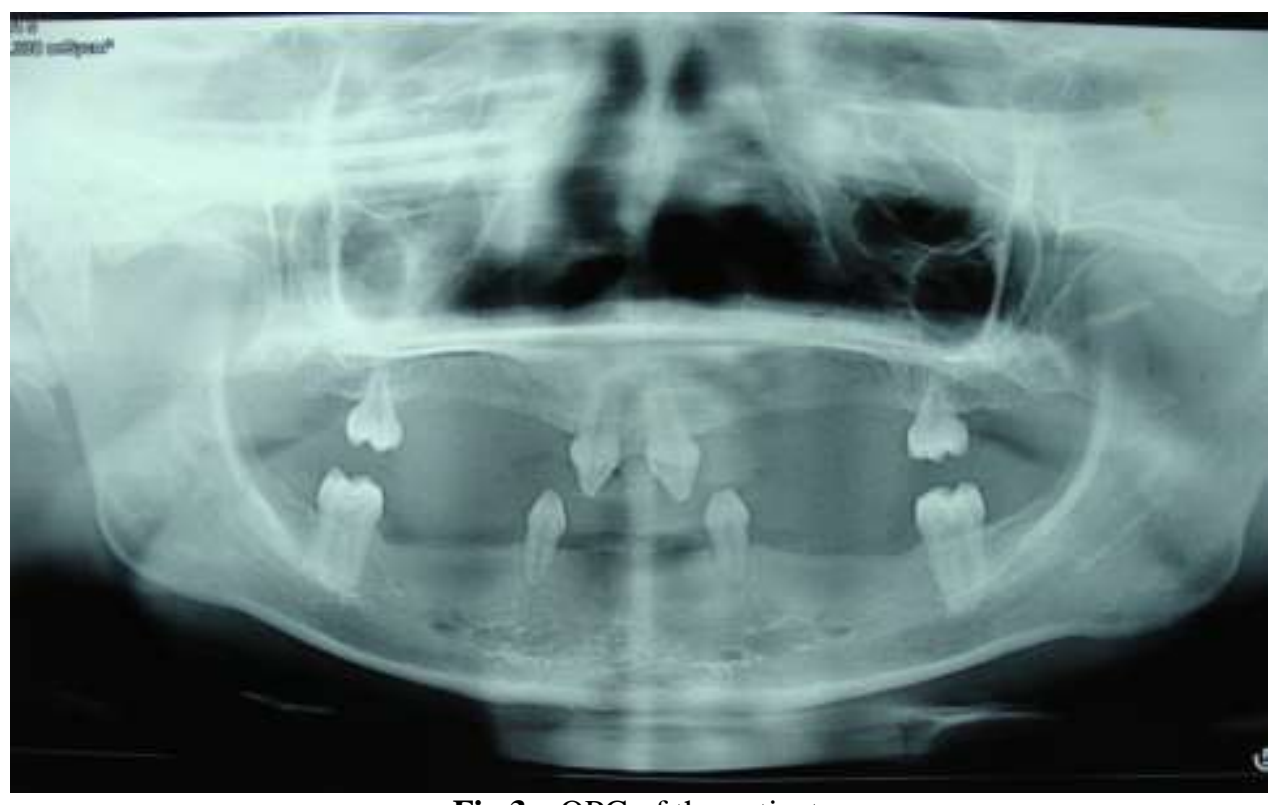

Fig.3:- OPG of the patient

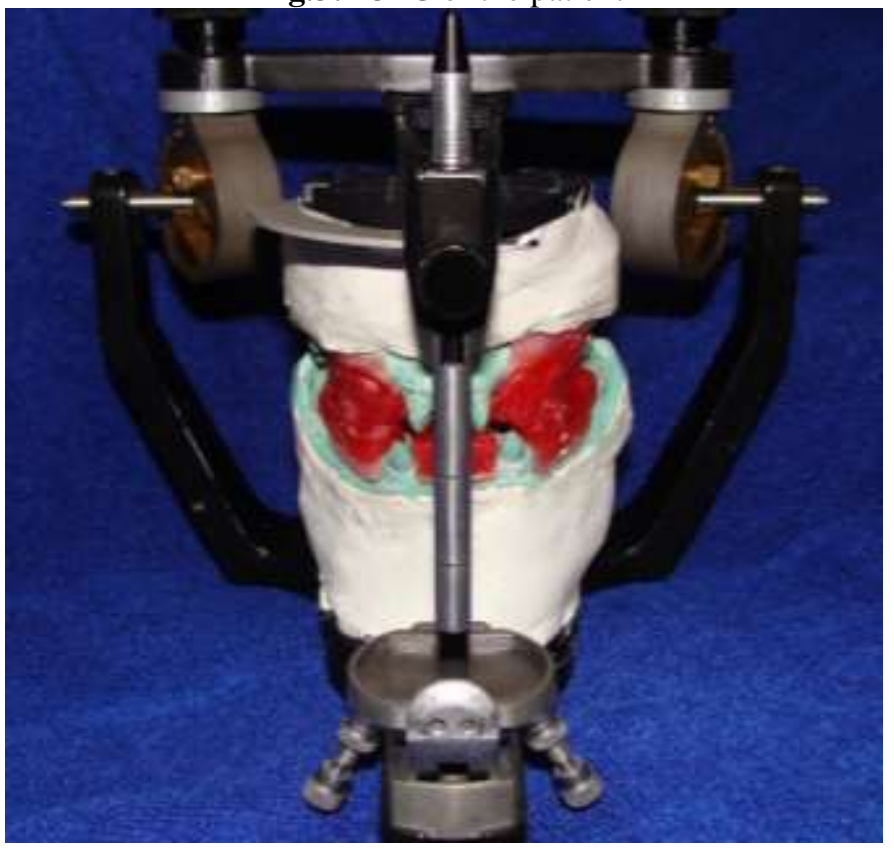

Fig.4:- Facebow transfer and Jaw relation

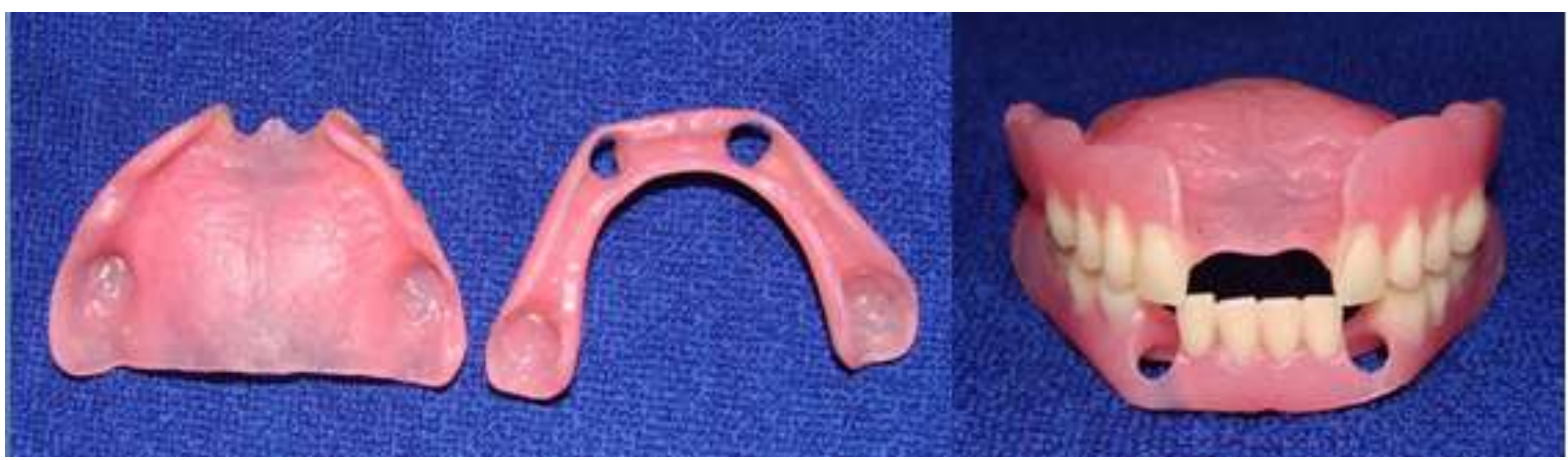

Fig.5:-Polished and finished Overdentures 


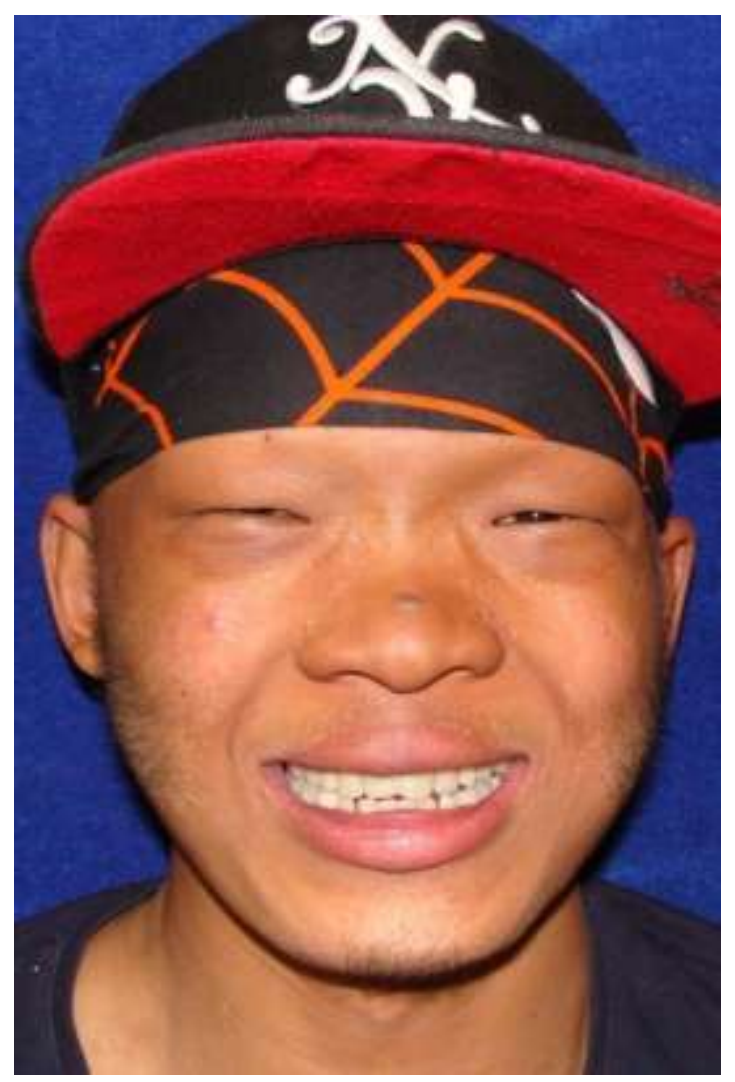

Fig.6:- Post -Op photo after rehabilitation

\section{Discussion:-}

Prosthetic rehabilitation of patients with ectodermal dysplasia is an ordinary process. Early and extensive dental treatment is needed throughout childhood because of the absence of most of the deciduous and permanent teeth. A multi- disciplinary team approach to management of these patients is recommended.

Sarwer et al ${ }^{5}$ reported greater dissatisfaction with facial appearance, lower self-esteem, and concern regarding quality of life in individuals born with craniofacial anomalies, as compared with non-facially disfigured adults. FPD's are not used in ED patients due to younger age and few numbers of teeth. Complete dentures are avoided due to instability and insufficient retention from the hypoplastic alveolar ridges and xerostomia ${ }^{2,3}$. Implants are avoided due to less bone volume available and in this case the cost of treatment. The patient was also reluctant to undergo any surgical intervention ${ }^{4}$. As the teeth were present for support, it was decided to rehabilitate the patient with a tooth supported over-denture prosthesis. Osseo-integrated implants should be an alternative treatment in older patients with ectodermal dysplasia.

\section{Conclusion:-}

Early intervention affords the child the opportunity to develop normalforms of speech, chewing, and swallowing; normal facial support; improved temporomandibular joint function; and improved self-esteem. 2 It is important that these individuals receive dental treatment at an early age for physiologic and psychosocial reasons. Adaptation to the prosthesis depends on various factors as capability of the specialist, age of the patient, and cooperation in a growing child. A removable partial denture or an overdenture is often suitable treatment of choice, because of the need to easily modify the intra oral prosthesis during rapid growth periods. Also these treatment options are easy, affordable, and reversible rehabilitation methods. 


\section{References:-}

1. Neville BW, Douglas DD, Allen CM, Bouquot E. Oral and maxillofacial pathology. 1st ed. Philadelphia: Saunders; 1995. p. 541-3.

2. A.Pigno Mark, B. Blackman Ronald, J.Cronin Robert and Cavazos Edmund. Prosthodontic management of Ectodermal dysplasia: a review of the literature; J Prosthet Dent, November 1996; 76(5):541-545.

3. Rahn O Arthur, Heartwell M Charles., Textbook of complete dentures, 5th ed. University of Michigan: BC Decker; 2002, p 499-500.

4. Jumber JF et al., An atlas of overdenture and attachments, 10th ed., University of Michigan: Quintessence Pub. Co., 1981,p 141-142.

5. Hickey AJ, Vergo TJ Jr. Prosthetic treatments for patients with ectodermal dysplasia. J Prosthet Dent 2001;86: 364-8. 